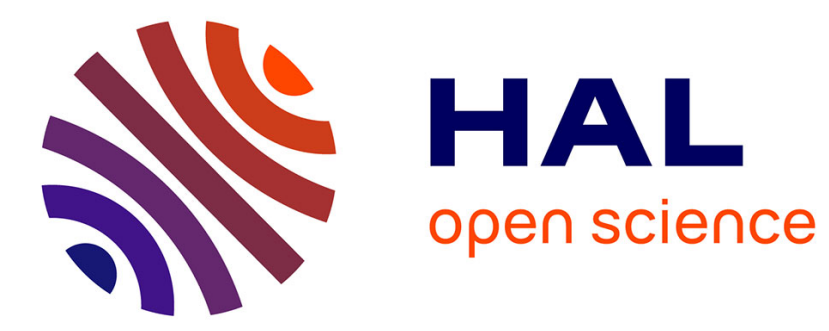

\title{
Rockfill shear strength evaluation: a rational method based on size effects
}

Étienne Frossard, Wei Hu, Christophe Dano, Pierre-Yves Hicher

\section{To cite this version:}

Étienne Frossard, Wei Hu, Christophe Dano, Pierre-Yves Hicher. Rockfill shear strength evaluation: a rational method based on size effects. Geotechnique, 2012, 62 (5), pp.415-427. 10.1680/geot.10.P.079 . hal-01007268

\section{HAL Id: hal-01007268 \\ https://hal.science/hal-01007268}

Submitted on 18 Apr 2017

HAL is a multi-disciplinary open access archive for the deposit and dissemination of scientific research documents, whether they are published or not. The documents may come from teaching and research institutions in France or abroad, or from public or private research centers.
L'archive ouverte pluridisciplinaire HAL, est destinée au dépôt et à la diffusion de documents scientifiques de niveau recherche, publiés ou non, émanant des établissements d'enseignement et de recherche français ou étrangers, des laboratoires publics ou privés. 


\title{
Rockfill shear strength evaluation: a rational method based on size effects
}

\author{
E. FROSSARD* ${ }^{*}$ W. HU $\dagger$, C. DANO $\dagger$ and P.-Y. HICHER $\dagger$
}

The shear strength of coarse granular materials, widely used in civil works such as rockfill in dam construction, is seldom measured because of severe practical experimental limitations. This paper presents an original method for evaluating the shear strength of such materials, based on size effects in granular materials affected by grain breakage according to fracture mechanics. Through a general size effect relation operating on shear strength envelopes, this method makes it possible to determine the shear strength of a coarse-grained granular material from the measured properties of a finergrained granular material made of the same mineral. In the paper, the method is explicitly proved, taking into account the statistical distribution of breakage resistances of particles with different sizes, within materials that can be considered as physically similar, particularly having parallel grain size distributions and the same compactness. A wide set of independent experimental results is shown to validate the method consistently.

KEYWORDS: dams; particle crushing/crushability; shear strength
La résistance au cisaillement des matériaux granulaires à gros grains largement utilisés en génie civil, tels les enrochements dans la construction de barrages, fait rarement l'objet de mesures du fait de limitations pratiques lourdes qui pèsent sur l'expérimentation. Cet article présente une méthode originale pour évaluer la résistance au cisaillement de tels matériaux, fondée sur les effets d'échelle survenant dans les matériaux granulaires affectés par la rupture de granulats suivant la Mécanique de la Rupture. Au moyen d'une Relation d'Effet d'Echelle assez générale, qui opère sur les courbes intrinsèques, cette méthode permet de déterminer la résistance au cisaillement d'un matériau granulaire à gros grains, à partir de mesures effectuées sur un matériau granulaire plus fin, constitué de la même matière minérale. Dans l'article, cette méthode est explicitement prouvée, en tenant compte des distributions statistiques des résistances à la rupture des granulats de différentes dimensions, au sein de matériaux granulaires qui se correspondent en similitude physique, avec en particulier des granulométries semblables et la même compacité. La méthode est enfin validée sur un large ensemble de résultats expérimentaux indépendants.

\section{BACKGROUND}

The construction of large civil works involving coarsegrained materials, such as rockfill dams (Fig. 1), is increasing worldwide (ICOLD, 2002). Traditionally, rockfill materials have seldom been tested for shear resistance, because of the size of the apparatus required, and the corresponding costs and delays for testing, even for small-sized rockfill. For example, for a $0-250 \mathrm{~mm}$ rockfill, a representative cylindrical probe for a triaxial test should measure about $1.5 \mathrm{~m}$ in diameter by $3 \mathrm{~m}$ high, and weigh more than $10 \mathrm{t}$. However, the trend towards larger works, such as higher rockfill dams with steeper slopes, should be associated with improved knowledge of these materials for stability assessment, and particularly knowledge of their shear resistance. Significant incidents have recently marked the commissioning of various large rockfill dams (CBDB-ICOLD, 2007), attributed to excessive unforeseen deformations required to mobilise the resisting forces necessary for static equilibrium, under normal service conditions.

Concern is rising within the profession to return to more rational approaches in their design, and particularly engineering approaches through structural analysis and relevant material testing, as should be done for any large civil engineering structure. This concern also underlines a growing need for progress in the knowledge and rational mastery of the behaviour of rockfill and large embankment works, and is shared by other sectors of construction, such as large

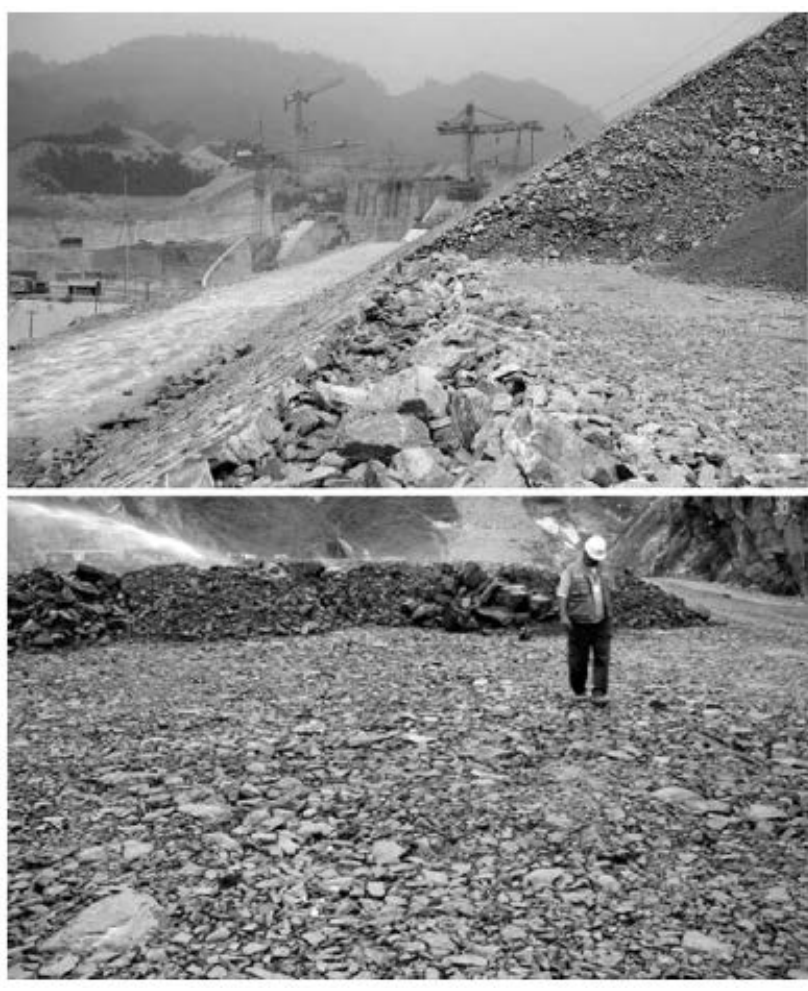

Fig. 1. Typical rockfills used in dam construction

linear embankment works in highways, railways and marine works.

Pioneering experimental work in large-scale testing of a wide range of different materials was developed in the 
1960s, together with the development of large rockfill dam construction in the Americas, by Marsal in Mexico (Marsal, 1967, 1972), and at approximately the same time in California by Marachi and colleagues (Marachi et al., 1969, 1972; Becker et al., 1972). Table 1 summarises the main features of the triaxial apparatus developed by these investigators.

Other large testing equipment with comparable features was later implemented worldwide, but its operation remains outside the scope of current geotechnical laboratories, and the data available are quite scarce (Duncan, 2004).

Smaller devices have also been used to provide interesting results concerning the behaviour of rockfills (Charles \& Watts, 1980; Barton \& Kjaernsli, 1981; Bolton, 1986; Indraratna et al., 1998), of unsaturated gravels and rockfills (Chávez \& Alonso, 2003), and of the dynamic behaviour of ballasts (Indraratna et al., 1998; Lackenby et al., 2007).

However, the ordinary rockfills commonly used in large dam construction, with maximum grain sizes typically between $250 \mathrm{~mm}$ and $800 \mathrm{~mm}$ (and sometimes larger), remain out of range of the largest apparatuses mentioned above. This background justifies efforts to find a method to evaluate the shear strength of very coarse granular materials from measurements performed on finer gradations of the same mineral constituents. The original method detailed here below provides a response to this need. It is based upon the key concept that a characteristic gradation dimension (e.g. the mean grain diameter or maximum grain diameter) affects the mechanical behaviour of the granular mass, by controlling the amount of grain breakage under loading. This method (Frossard, 2006, 2008, 2009a, 2009c) results from an in-depth review of numerous past experimental results on rockfill in the light of current knowledge of the mechanics of materials, and particularly fracture mechanics, during recent research projects on granular fill behaviour (Frossard, 2005a).

\section{SIZE EFFECT IN GRANULAR MATERIALS USED IN CIVIL WORKS: PREVIOUS WORK}

The size effect can generally be described as the dependence of a material intrinsic property on a characteristic sample dimension (e.g. volume or diameter). Such a phenomenon is encountered in many engineering fields, including quasi-brittle geomaterials in civil engineering (concrete, rock and soil), and was investigated long ago in geomechanics for its incidence in similarity relations (Weber, 1971). Here, as a result from fracture mechanics, the size effect can be expressed by the fact that, statistically, the intrinsic strength of a specimen decreases when its size increases (Bazant \& Planas, 1998). Furthermore, as this essential result is related to the development of preexisting flaws and microcracks within the material of the specimen, the way these flaws and cracks are distributed will affect the variability of the strength of a brittle material. On the basis of data on brittle materials, a statistical approach was proposed by Weibull (1951) to describe brittle material strength and its variability, a specific parameter being attached to the variability in specimen strength in the resulting Weibull distribution. In granular materials the size effect affects the crushing resistance of individual particles submitted to contact forces and, as a consequence, the mechanical behaviour of the whole granular mass.

\section{Size effect for individual grains}

Experimental results in the literature (e.g. Marsal, 1972; Lee, 1992; Nakata et al., 1999; Miura et al., 2003) outline how, statistically, the intrinsic strength of an individual particle decreases as the particle size increases (Figs 2 and 3 ). The strength of the particle is commonly determined by applying a compressive load on it, placed between two stiff platens. It is calculated from the maximum load reached before global failure of the particle (Fig. 2). This specific feature of grain behaviour has to be attributed to initial microcracks randomly distributed in size and orientation within the particles. They are, statistically, larger in large grains (Fig. 4). Physically, during loading, the initial microcracks grow and interconnect to form a macrocrack at failure. Griffith's theory for brittle materials (Griffith, 1921) established that the strength is inversely proportional to the square root of the initial microcrack length. McDowell \& Bolton (1998) suggested later that the gradation of crushable soils tends towards a fractal distribution because of particle crushing.

\section{Size effect in granular materials}

Experimental size effects were clearly apparent in a series of triaxial tests carried out by Marsal (1967) on specimens of different sizes, as well as in a series of crushing tests on particles of different sizes. Similarly, Marachi et al. (1969) performed an outstanding series of triaxial tests on three kinds of rockfill specimen of different sizes. For each material, three specimen groups of different sizes were reconstituted with the same compactness and closely parallel grain size distributions (Fig. 5), adjusted so that the mean and maximum grain sizes were in proportion to the specimen sizes (fine-, medium- or coarse-grained; Table 2).

At the end of the shearing phase, evolution of the grada-

Table 2. Key features of multi-scale series of triaxial tests performed by Marachi et al. (1969)

\begin{tabular}{l|c|c|c}
\hline Type of material & $\begin{array}{c}\text { Material } \\
D_{\max }: \text { mm (inches) }\end{array}$ & \multicolumn{2}{|c}{ Specimen for testing } \\
\cline { 3 - 4 } & & $\begin{array}{c}\text { Diameter: mm } \\
\text { (inches) }\end{array}$ & $\begin{array}{c}\text { Height: } \\
\mathrm{mm}\end{array}$ \\
\hline Coarse grained & $152(6)$ & $915(36)$ & 2286 \\
Medium grained & $51(2)$ & $305(12)$ & 762 \\
Fine grained & 12 & $71(2 \cdot 8)$ & 178 \\
\hline
\end{tabular}

Table 1. Key features of large triaxial apparatus of Marsal and Marachi et al.

\begin{tabular}{l|c|c|c|c|c}
\hline \multirow{2}{*}{ References } & \multicolumn{3}{|c|}{ Sample features } & \multicolumn{2}{c}{ Maximum loading range } \\
\cline { 2 - 5 } & Diameter: $\mathrm{mm}$ & Height: $\mathrm{mm}$ & Max. grain size: $\mathrm{mm}$ & Confining pressure: MPa & Axial load: $\mathrm{kN}$ \\
\hline Marsal $(1967,1972)$ & 1130 & 2500 & 180 & 2.5 & 15000 \\
Marachi et al. $(1969,1972)$ & 915 & 2286 & 152 & 5 & 18000 \\
\hline
\end{tabular}




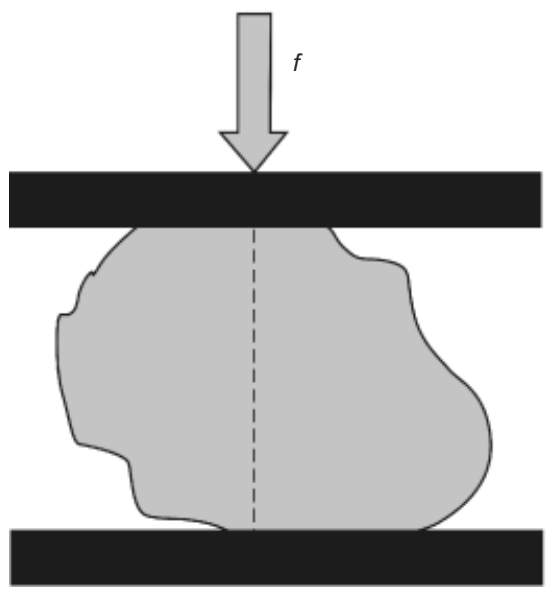

Fixed platen

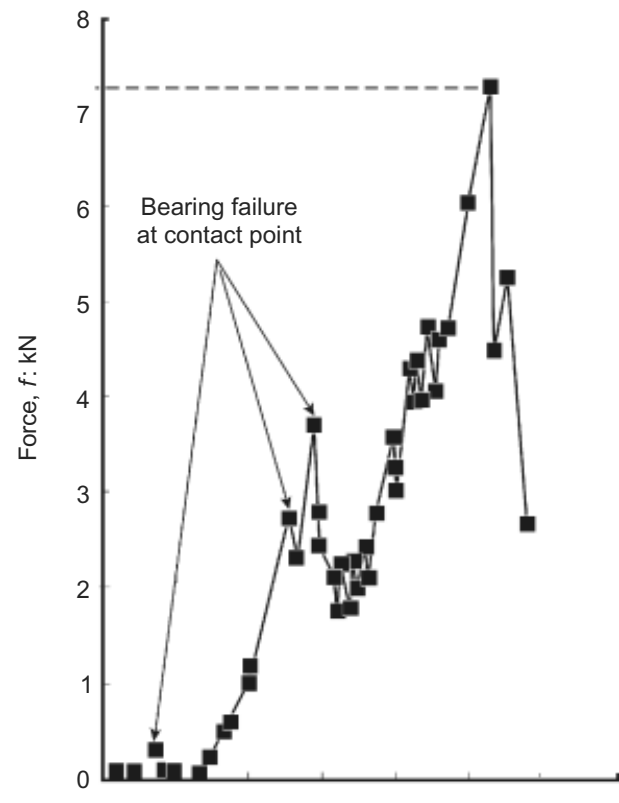

Platen displacement

Fig. 2. Method for crushing test on particles (after Lee, 1992)

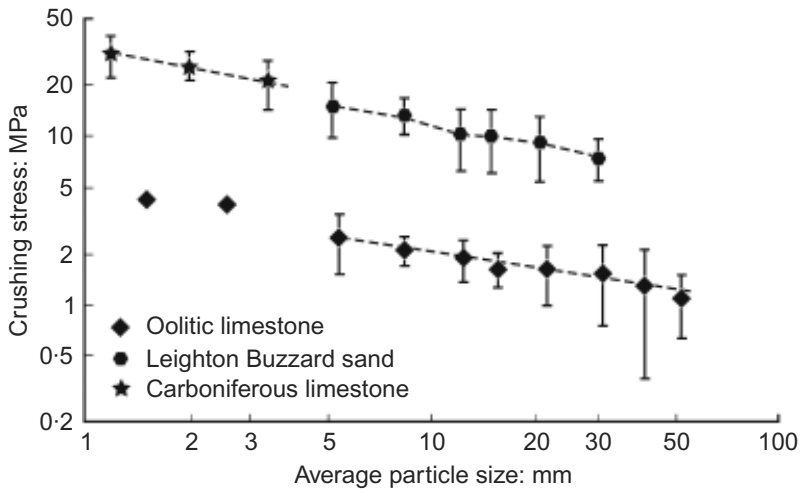

Fig. 3. Experimental evidence of size effect in strength of individual grains (Lee, 1992). tions was measured, by determination of a global grain breakage factor determined by the difference between the initial and final gradations (according to the definition and procedure detailed in Marsal, 1972). Marachi et al. (1969) found that the reduction observed in the value of the internal friction angle can be closely related to the grain breakage intensity, particularly developed in large specimens. Their results showed clearly that the maximum shear strength of the specimen decreases and the amount of particle breakage increases when the particle size increases. Similar relationships were obtained for the three different granular materials, the only difference being in the intensity of particle crushing. One other key experimental result of these investigations (Fig. 6) was that, within each of the three families of similar granular materials, the correspondence between the internal friction and the amount of grain breakage was

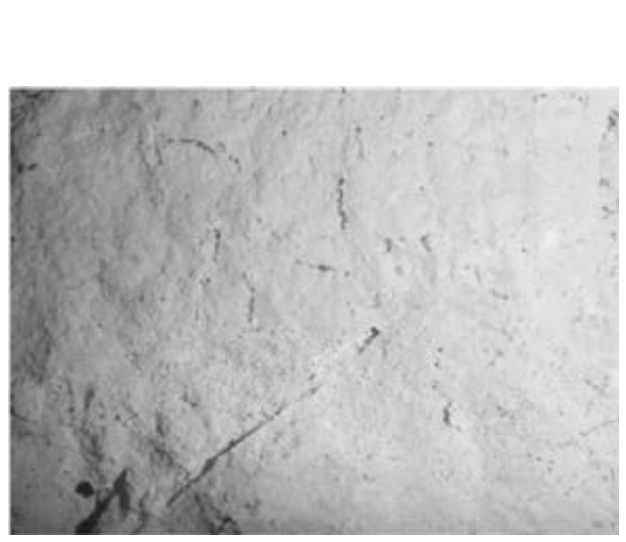

(a)

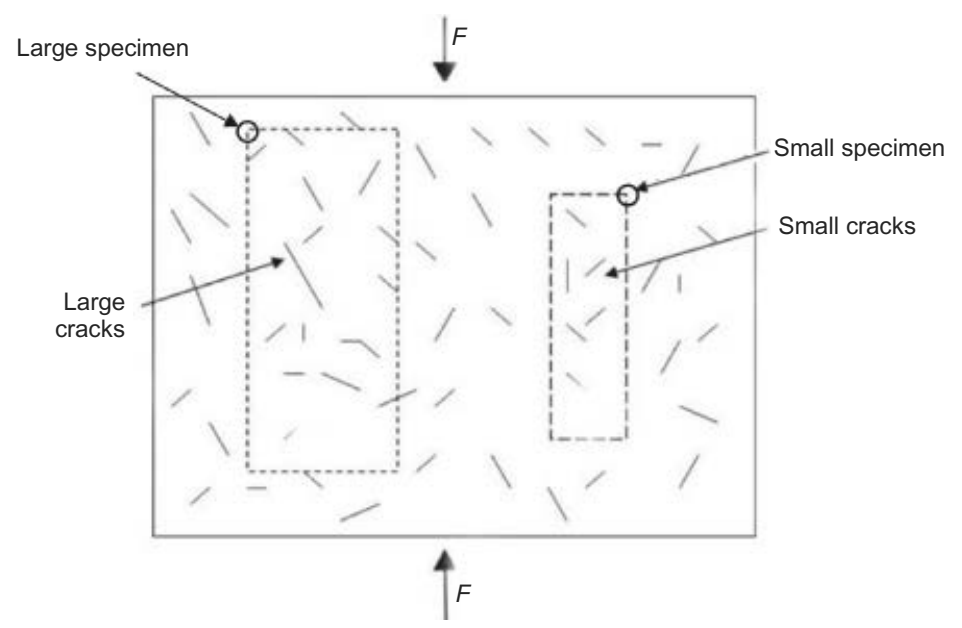

(b)

Fig. 4. Schematisation of origin of size effect: (a) close-up of freshly cut rock surface, showing flaws, cracks and pore cavities; (b) within a given mineral matrix, the large specimen will tend statistically to include larger flaws or cracks affecting its crushing resistance than the smaller specimen 


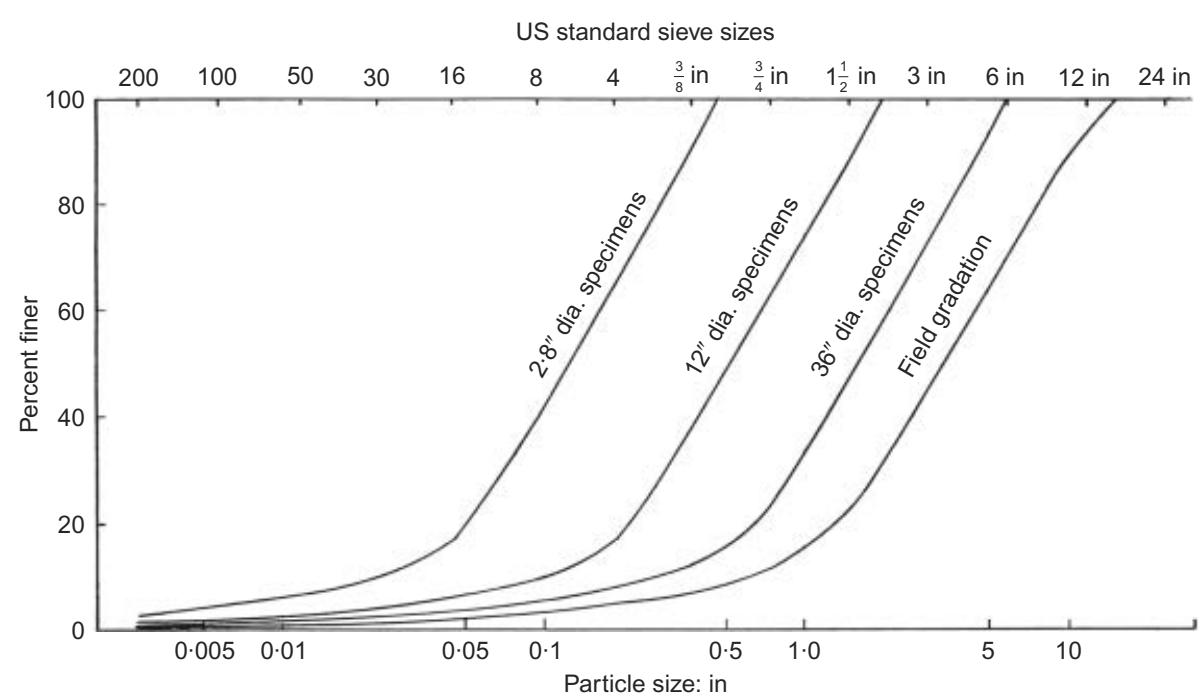

(a)

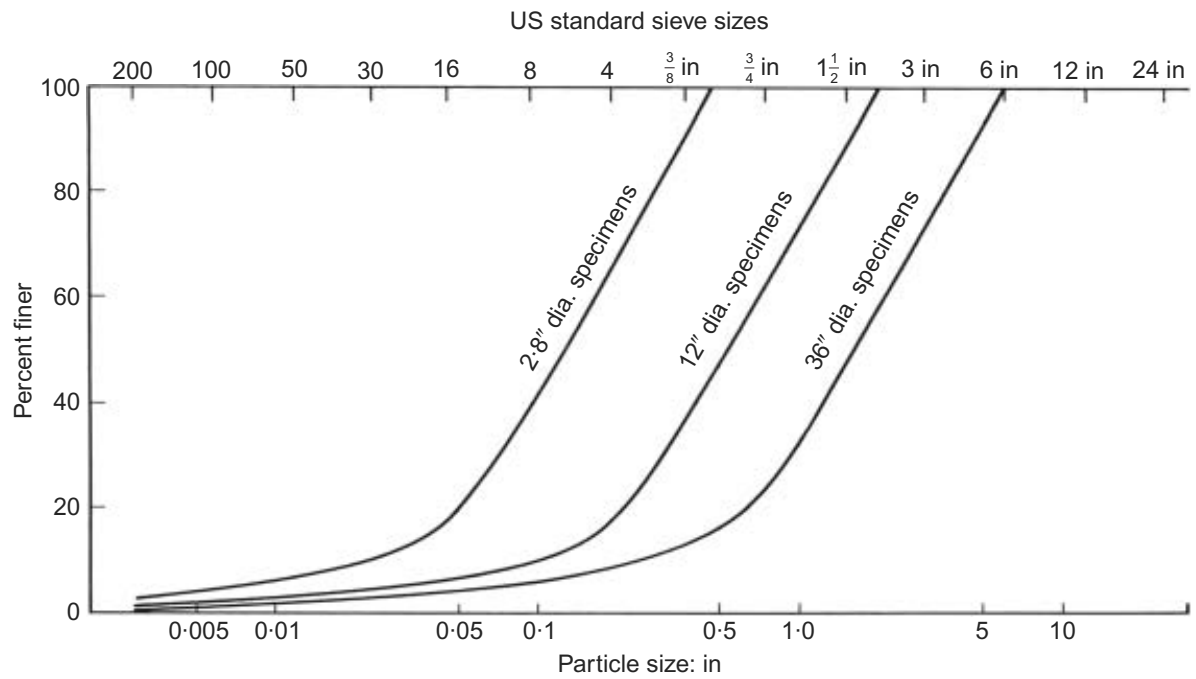

(b)

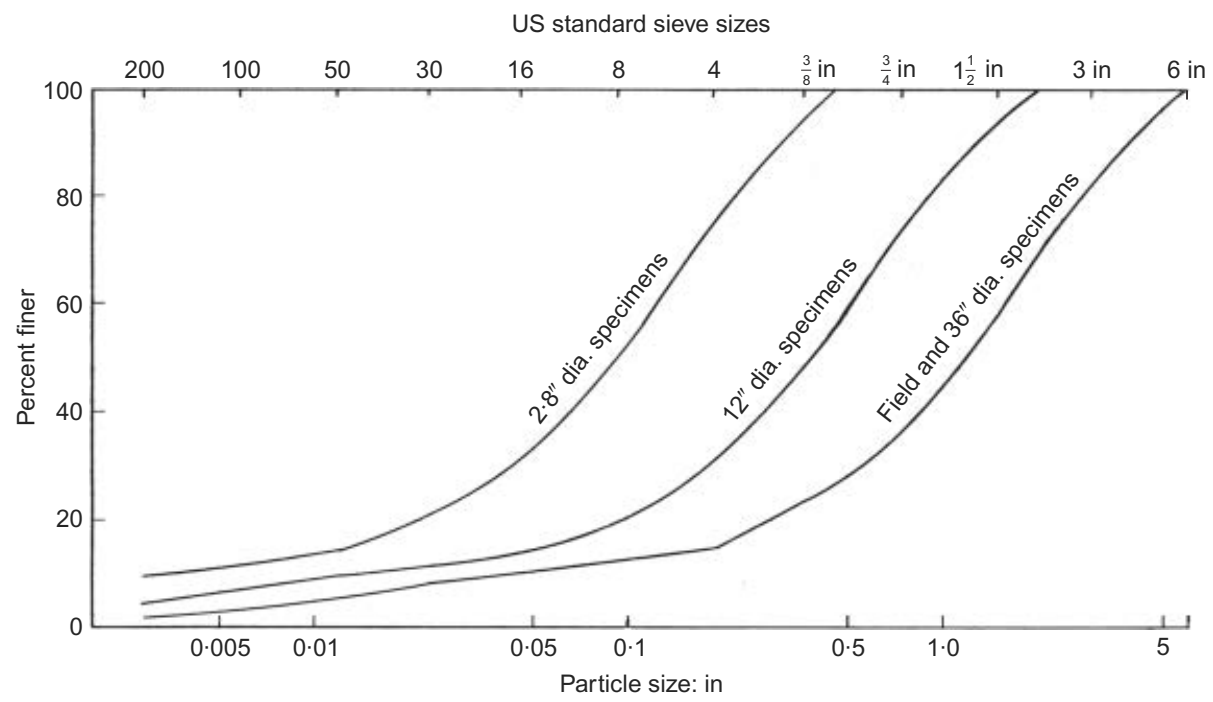

(c)

Fig. 5. Rockfill grain size distributions for different specimen diameters of three materials tested by Marachi et al. (1969): (a) Pyramid Dam material; (b) crushed basalt; (c) Oroville Dam material $(1$ in $=25.4 \mathrm{~mm})$

found to be unique, regardless of the characteristic size (coarse-, medium- or fine-grained), if all the specimens within one family were given the same initial compactness.

Hardin (1985), Lee (1992), Coop \& Lee (1993), Biarez \&
Hicher (1997), Daouadji et al. (2001), Deluzarche \& Cambou (2006) and Lade \& Bopp (2005) also studied the breakage of particles in granular media, which was found to be a source of size effects in crushable granular materials. 


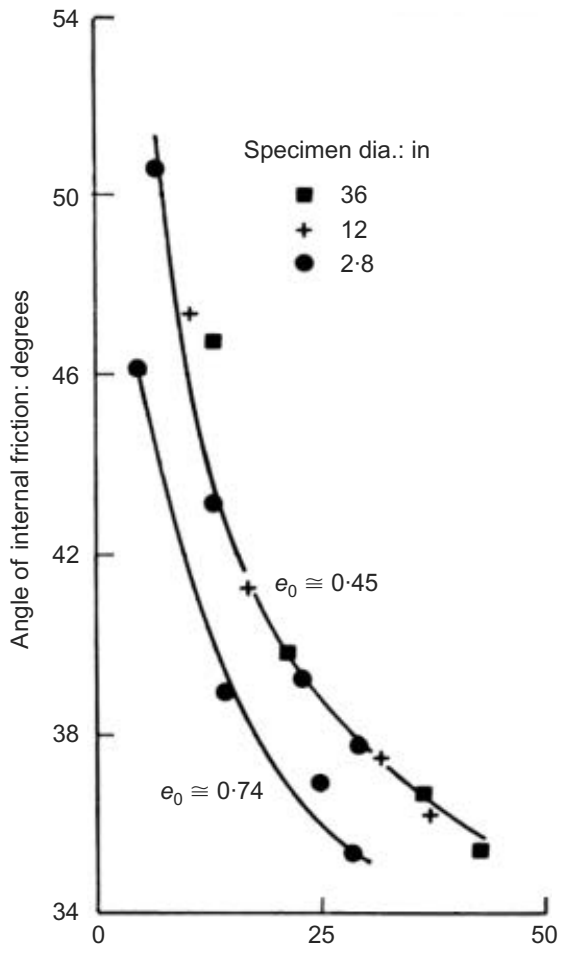

(a)

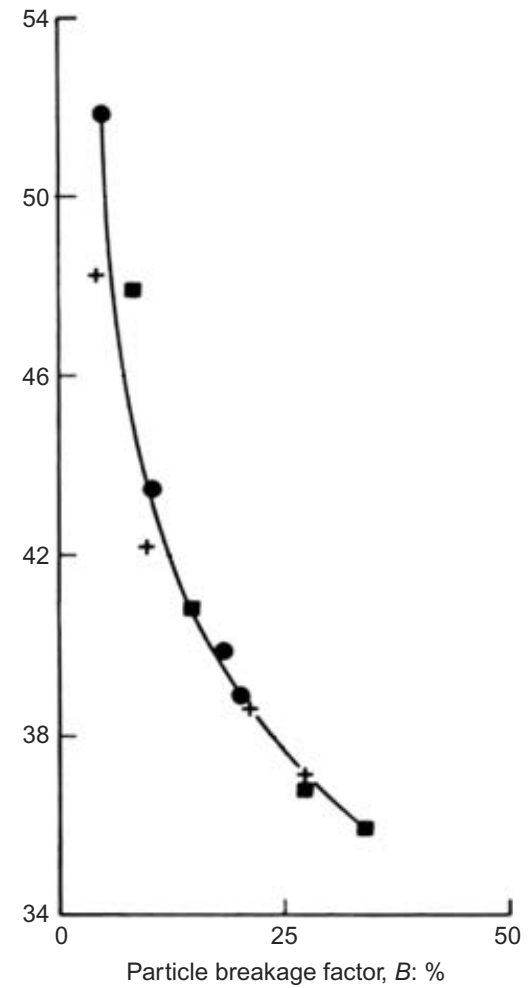

(b)

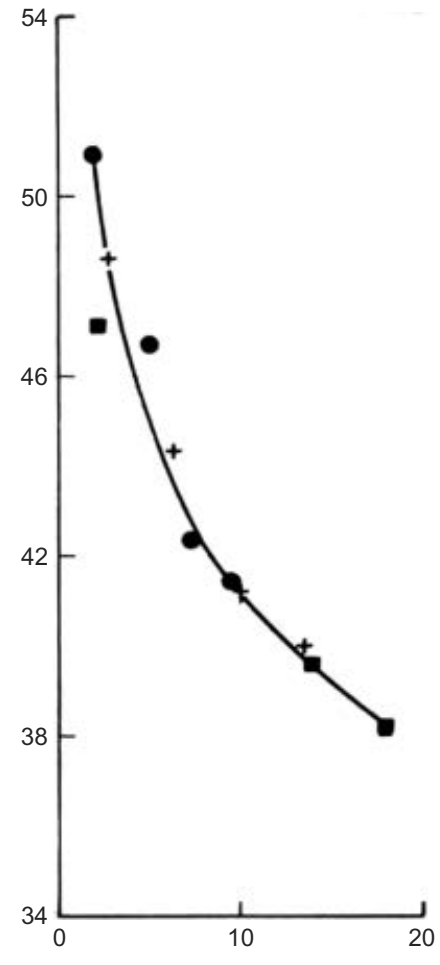

(c)

Fig. 6. Internal friction angle against grain breakage factor for different specimen sizes of three materials tested by Marachi $e t$ al. (1969): (a) Pyramid Dam material; (b) crushed basalt; (c) Oroville Dam material (1 in = 25.4 mm)

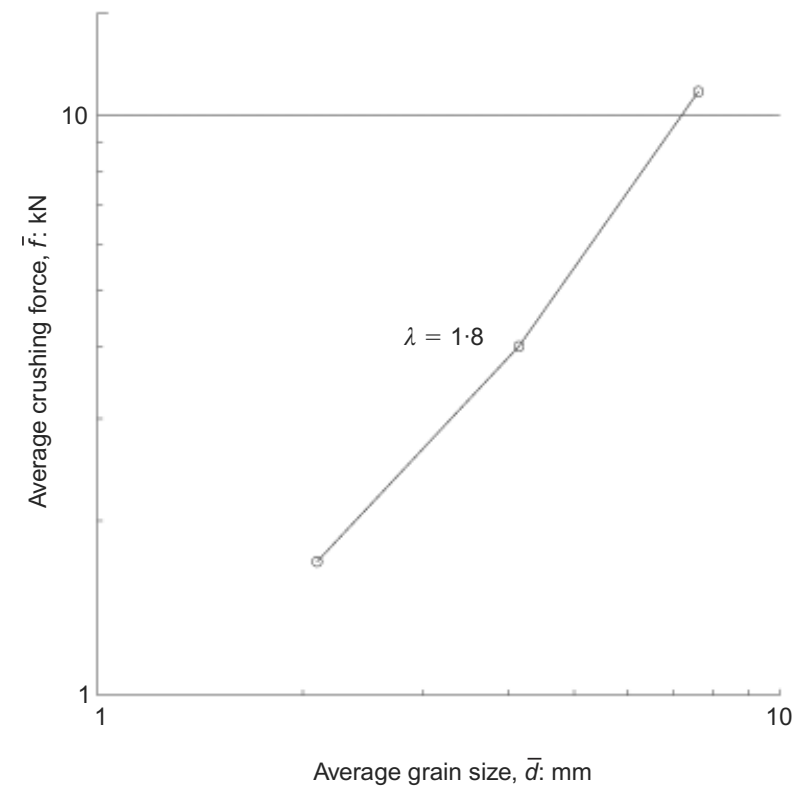

Fig. 7. Experimental relation between average grain size and particle-crushing load for San Angel basalt (redrawn from data presented by Marsal, 1967)

\section{PROPOSED SIZE EFFECT RELATIONS BASED ON GRAIN BREAKAGE}

Assumed key features of grain breakage

On the basis of experimental data, Marsal (1967, 1972) proposed representing the average experimental crushing strength $\bar{f}$ by a power function of the average diameter $\bar{d}$ of the particles (Fig. 7)

$$
\bar{f}=\eta \bar{d}^{\lambda}
$$

where $\eta$ and $\lambda$ are experimental constant material values.

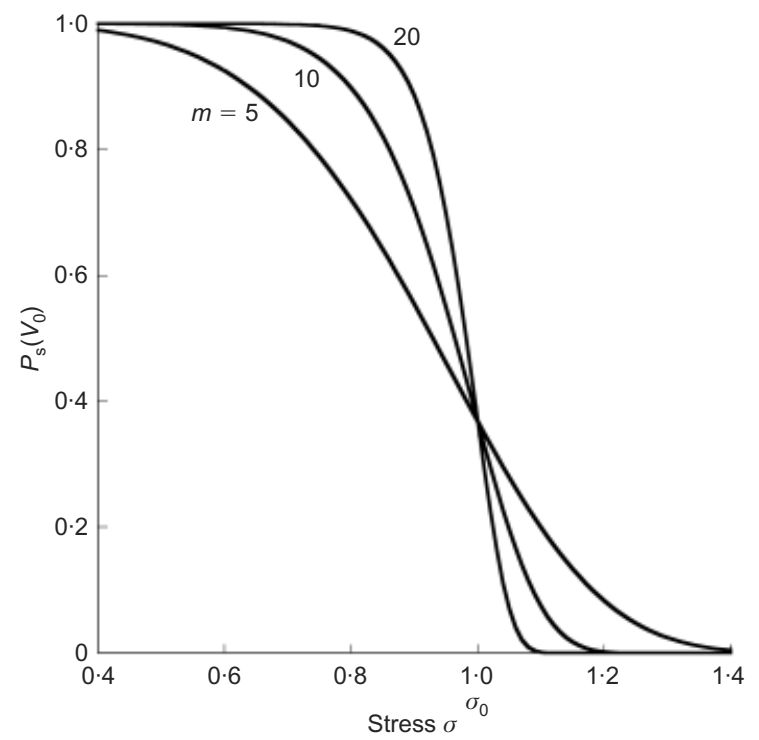

Fig. 8. Influence of Weibull modulus $m$ on shape of Weibull distribution

Grain-crushing statistics can also be described by a Weibull distribution, considering the probability of survival within a population of brittle objects exposed to loading conditions (Weibull, 1951). In this approach, the probability of survival $P_{\mathrm{s}}(V, \sigma)$ within a set of brittle particles defined by their volume $V$ and submitted to an applied stress $\sigma$ is given by

$$
P_{\mathrm{s}}(V, \sigma)=\exp \left[-\frac{V}{V_{0}}\left(\frac{\sigma}{\sigma_{0}}\right)^{m}\right]
$$

where $V_{0}$ is a given reference volume, and $\sigma_{0}$ corresponds to the applied stress for which $P_{\mathrm{s}}\left(V_{0}\right)=1 / e=0 \cdot 37$, meaning that $37 \%$ of the specimens (with volume $V_{0}$ ) survived the 
loading without breaking. This equation is represented in Fig. 8 for $V=V_{0}$ and for different values of the material parameter $m$. The smaller $m$ is, the more disperse is the strength distribution. The two representations, Marsal (equation (1)) and Weibull (equation (2)), can be connected in order to relate the parameters $\lambda$ and $m$. Indeed, as the grain volume $V$ is statistically proportional to the cube of its diameter $d$, if failure is statistically defined by a given probability of survival, then the corresponding average crushing strength will be proportional to a power function of the diameter $d$ (McDowell \& Bolton, 1998)

$$
P_{\mathrm{s}}(V, \sigma) \text { fixed } \Rightarrow \sigma \propto d^{-3 / m}
$$

Given that the mean stress $\sigma$ inside the grain is proportional to the applied force $f$ during loading, divided by the mean section of the grain, which itself is statistically proportional to the square of its diameter, then merging the two approaches gives a simple means to set, for a given material, a representative Weibull distribution. From equations (1), (2) and (3) the following relation is derived

$$
\lambda=2-\frac{3}{m} \text { or } m=\frac{3}{2-\lambda}
$$

In the range of materials investigated by Marsal (1967, 1972), the exponent $\lambda$ was found to be between 1.2 and 1.8 , corresponding to a Weibull modulus $m$ between 4 and 15, with a central value of $\lambda$ of about $1 \cdot 5$, corresponding to a Weibull modulus $m$ central value equal to 6 . These central values are not a simple random result; they correspond precisely to a distribution of the sizes of flaws or microcracks inside particles, for which the significant flaw or microcrack size governing their failure is found to be statistically proportional to their diameter.

In equations (2) and (3), $\sigma$ corresponds to the mean stress applied on one grain. The core assumption of the approach developed herein is that the significant stress applied to one grain within a granular assembly may be considered as being proportional to the average macroscopic stress applied to the granular material. Then, in the above situation of a central distribution of flaws, the limit of average macroscopic stress that the granular medium can withstand before crushing will be inversely proportional to the square root of a characteristic grain diameter.

\section{Basic size effect relation for simple particle sets}

Coming back to the more general situation, consider particles from two sets of particles, A and B, issued from the same homogeneous mineral stock, with similar grain shapes, and characteristic diameters $d_{\mathrm{A}}$ and $d_{\mathrm{B}}$, described by equations (1)-(4).

(a) Submit the particles in these two sets to crushing forces $f_{\mathrm{A}}$ and $f_{\mathrm{B}}$.

(b) In order to obtain the same probability of ruptures of particles within the two sets, $f_{\mathrm{A}}$ and $f_{\mathrm{B}}$ must be adjusted to the same proportion of the average resistance of particles in sets $\mathrm{A}$ and $\mathrm{B}$, resulting in the following basic size effect relation regarding grain breakage for simple particle sets (Frossard, 2009d).

$$
f_{\mathrm{B}}=f_{\mathrm{A}}\left(\frac{d_{\mathrm{B}}}{d_{\mathrm{A}}}\right)^{\lambda} \text { or } f_{\mathrm{B}}=f_{\mathrm{A}}\left(\frac{d_{\mathrm{B}}}{d_{\mathrm{A}}}\right)^{2-3 / m}
$$

Size effect relation for granular materials (Table 2)

In a granular material, the macroscopic stresses may be related to the set of local interparticle contact forces, integrated in a representative volume. Following the LoveWeber approach of stress averaging, the macroscopic stress tensor $\sigma_{i j}$ can be obtained by the integration of contact forces and branch vectors for all contacts (Love, 1927; Weber, 1966; Christofferson et al., 1981; Rothenburg \& Selvadurai, 1981; Chang \& Hicher, 2005)

$$
\boldsymbol{\sigma}=\frac{1}{V} \sum_{n<p \leqslant N} \boldsymbol{f}_{(n / p)} \otimes \boldsymbol{l}_{(n / p)}
$$

or

$$
\sigma_{i j}=\frac{1}{V} \sum_{n<p \leqslant N} f_{i(n / p)} \cdot l_{j(n / p)}
$$

where $\boldsymbol{f}_{(n / p)}$ is the contact force exerted by particle $n$ on particle $p ; \boldsymbol{l}_{(n / p)}$ is the branch vector joining the centres of particles in contact, from particle $n$ towards particle $p$; and $N$ is the total number of particles occupying volume $V$ in the granular material under consideration.

Let us now consider two granular materials $\mathrm{A}$ and B, geometrically similar and issued from the same homogeneous mineral stock (Fig. 9), and analyse the relations resulting from this similarity, which is assumed to be a perfect one. First, these two similar granular media display similar grain shapes, the same density and parallel grain size distributions (Fig. 10). The geometric correspondence between media $\mathrm{A}$ and $\mathrm{B}$, is ruled by a geometric similarity ratio $D_{\mathrm{B}} / D_{\mathrm{A}}$, where $D_{\mathrm{A}}$ and $D_{\mathrm{B}}$ are given characteristic sizes for media $\mathrm{A}$ and $\mathrm{B}$ respectively (e.g. maximum grain size $D_{\max }$, mean grain size $D_{50}$, or any other given characteristic diameter). For example, the diameters $d_{\mathrm{A}(p)}$ and $d_{\mathrm{B}(p)}$ for two homologous particles $p$, or the branch vectors between particles $n$ and $p$ in contact, or the volumes $V_{\mathrm{A}}$ and $V_{\mathrm{B}}$ occupied by homologous representative subsets of particles in granular media A and B are linked by

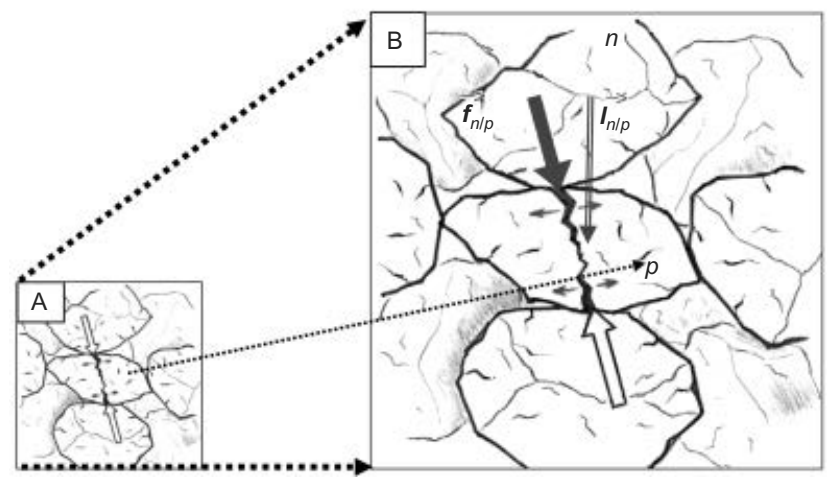

Fig. 9. Granular materials A and B with similar geometry

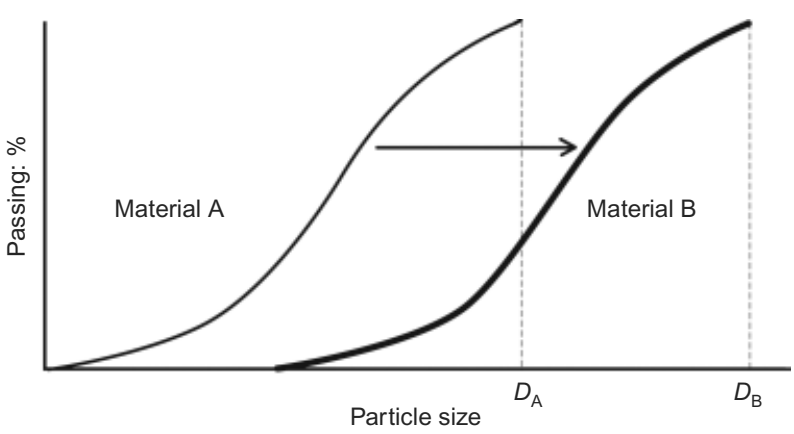

Fig. 10. Gradations of similar materials $A$ and $B$ 


$$
\begin{array}{r}
d_{\mathrm{B}(p)}=d_{\mathrm{A}(p)}\left(\frac{D_{\mathrm{B}}}{D_{\mathrm{A}}}\right) \\
\boldsymbol{l}_{\mathrm{B}(n / p)}=\boldsymbol{l}_{\mathrm{A}(n / p)}\left(\frac{D_{\mathrm{B}}}{D_{\mathrm{A}}}\right) \\
V_{\mathrm{B}}=V_{\mathrm{A}}\left(\frac{D_{\mathrm{B}}}{D_{\mathrm{A}}}\right)^{3}
\end{array}
$$

Regarding the forces and internal equilibrium in the two similar materials, some basic assumptions will be made. As the particles of both granular media are issued from the same mineral stock, the statistics of their crushing strengths are assumed to be described by the same Weibull distribution; and the friction coefficients at homologous contacts are assumed to be identical.

Consider now these similar granular media submitted to macroscopic stresses, close to limit equilibrium, inducing slow motion inside both media: the resulting contact forces induce some grain breakage. Consider the probability of failure of homologous particles $p$ in the two media under the effect of contact forces exerted by homologous particles $n$. Equation (5) shows that, in order to secure the same probability of grain breakage, the homologous contact forces should be in proportion to the crushing resistances of homologous particles $p$

$$
\boldsymbol{f}_{\mathrm{B}(n / p)}=\boldsymbol{f}_{\mathrm{A}(n / p)}\left(\frac{D_{\mathrm{B}}}{D_{\mathrm{A}}}\right)^{2-3 / m}
$$

As the scaling ratio is the same for all contact forces, this relation, valid locally for each contact force $\boldsymbol{f}_{(n / p)}$, also holds globally for the complete sets of contact forces $\{\boldsymbol{f}\}$.

$$
\left\{\boldsymbol{f}_{\mathrm{B}}\right\}=\left\{\boldsymbol{f}_{\mathrm{A}}\right\}\left(\frac{D_{\mathrm{B}}}{D_{\mathrm{A}}}\right)^{2-3 / m}
$$

Macroscopic stresses in the two granular materials derive from equation (6)

$$
\boldsymbol{\sigma}_{\mathrm{B}}=\frac{1}{V_{\mathrm{B}}} \sum_{n<p \leqslant N} \boldsymbol{f}_{\mathrm{B}(n / p)} \otimes \boldsymbol{l}_{\mathrm{B}(n / p)}
$$

and

$$
\boldsymbol{\sigma}_{\mathrm{A}}=\frac{1}{V_{\mathrm{A}}} \sum_{n<p \leqslant N} \boldsymbol{f}_{\mathrm{A}(n / p)} \otimes \boldsymbol{l}_{\mathrm{A}(n / p)}
$$

From equations (6)-(9), all the terms in the formula for the stress tensor in granular medium B may now be expressed as a function of the corresponding terms related to the similar granular medium A, resulting in the relation (Frossard, 2009d)

$$
\begin{aligned}
\boldsymbol{\sigma}_{\mathrm{B}} & =\left(\frac{D_{\mathrm{B}}}{D_{\mathrm{A}}}\right)^{-3 / m} \frac{1}{V_{\mathrm{A}}} \sum_{n<p \leqslant N} \boldsymbol{f}_{\mathrm{A}(n / p)} \otimes \boldsymbol{l}_{\mathrm{A}(n / p)} \\
& =\left(\frac{D_{\mathrm{B}}}{D_{\mathrm{A}}}\right)^{-3 / m} \boldsymbol{\sigma}_{\mathrm{A}}
\end{aligned}
$$

Equation (10) sets the relation between the macroscopic stress state tensors to be applied to granular media A and B in order to obtain the same probability of grain breakage during mechanical loading, and thus statistically the same amount of grain breakage during motion. This relation is called the size effect relation for macroscopic stresses regarding grain breakage (in geometrically similar granular media).

\section{SIZE EFFECT RELATION AND SHEAR STRENGTH \\ ENVELOPES \\ The link with shear strength envelopes}

Equations (8b) and (10) define a dynamic similitude within our granular materials A and B, which are already geometrically similar. In this framework, and with the basic assumptions made, if the system of internal contact forces $\left\{f_{\mathrm{A}}\right\}$ in granular material $\mathrm{A}$ is in limit equilibrium conditions, then the system of internal contact forces $\left\{f_{\mathrm{B}}\right\}$ in similar granular material $\mathrm{B}$ set by equation ( $8 \mathrm{~b}$ ) will be also in limit equilibrium conditions. Furthermore, the dynamic similitude set by equations (8) and (10), associated with the geometric similitude set by equation (7) and dry friction at contacts, reveals full compatibility with a kinematic similitude. So if slow motions that are kinematically similar are imposed on both media $\mathrm{A}$ and $\mathrm{B}$ under similar limit equilibrium conditions, equation (10) will link the stress states mobilised during the movements within the two materials, securing the same grain breakage intensity in both materials.

Provided that this situation of complete physical similarity is materially achievable, as a result of equation (10) the principal stress ratios $\left(\sigma_{1} / \sigma_{3}\right.$ etc.) will be the same in both $\mathrm{A}$ and $\mathrm{B}$, which means that the mobilised internal friction will be the same in both materials. This will also hold for the maximum stress mobilised during motion, or the shear strength envelope. So equation (10) will also apply to the stress states along the shear strength envelopes of granular materials $\mathrm{A}$ and $\mathrm{B}$, setting a direct correspondence between them: under confining stresses adjusted to produce the same amount of grain breakage, similar materials will display the same internal friction.

This last consequence of equation (10) also means that within a given family of similar materials with the same initial compactness, the correspondence between the amount of grain breakage and internal friction (i.e. the maximum internal friction mobilised during motion) will be unique, regardless of their characteristic size. This is precisely what was found experimentally by Marachi et al. (1969) (Fig. 6).

\section{Geometric and analytical correspondences set by the size} effect relation

Under these conditions, the size effect rule expressed in equation (10) establishes a simple and direct geometric correspondence between the shear strength envelopes of granular materials $\mathrm{A}$ and $\mathrm{B}$, as illustrated in Fig. 11. If a stress state $\left\{\sigma_{\mathrm{A}}\right\}$ is known on the shear strength envelope of

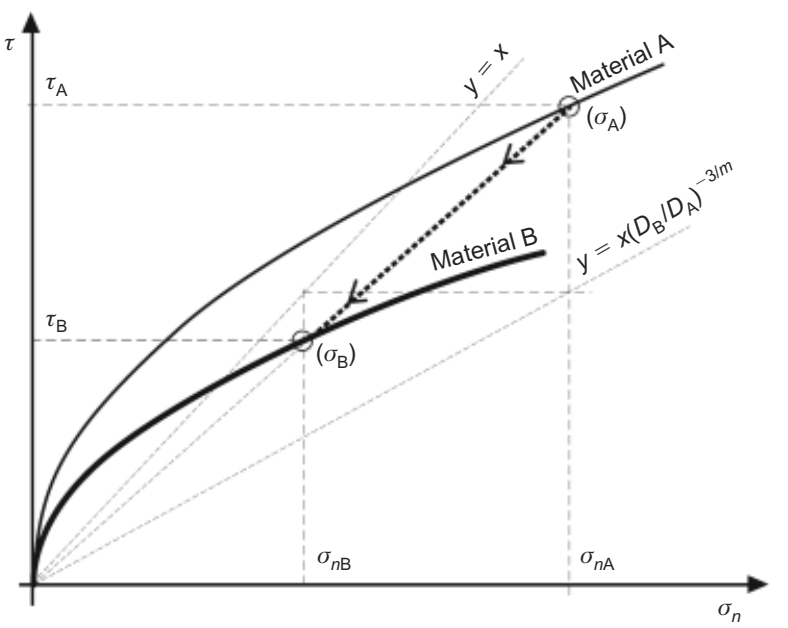

Fig. 11. Correspondence between shear strength envelopes of materials $A$ and $B$ set by size effect relation 
granular material $\mathrm{A}$, then the corresponding stress state $\left\{\sigma_{\mathrm{B}}\right\}$ on the shear strength envelope of granular material $\mathrm{B}$ can be obtained by applying a homothety with ratio $\left(D_{\mathrm{B}} / D_{\mathrm{A}}\right)^{-3 / m}$ on the vector $\boldsymbol{O}\left\{\sigma_{\mathrm{A}}\right\}$. So from the simple geometric constructions of Fig. 11, the shear strength envelope of granular material B can be obtained from that of granular material A, regardless of any analytical formulation of the shear strength envelope.

If the shear strength envelope of granular material A can expressed analytically as

$$
\tau_{\mathrm{A}}=f_{\mathrm{A}}\left(\sigma_{n \mathrm{~A}}\right)
$$

then by reversing equation (10), the following relations result between shear stresses and normal stresses in granular materials $\mathrm{A}$ and $\mathrm{B}$.

$$
\begin{aligned}
\tau_{\mathrm{A}} & =\tau_{\mathrm{B}}\left(\frac{D_{\mathrm{B}}}{D_{\mathrm{A}}}\right)^{3 / m} \\
\sigma_{n \mathrm{~A}} & =\sigma_{n \mathrm{~B}}\left(\frac{D_{\mathrm{B}}}{D_{\mathrm{A}}}\right)^{3 / m}
\end{aligned}
$$

Then equations (11) and (12) lead to

$$
\tau_{\mathrm{B}}=\left(\frac{D_{\mathrm{B}}}{D_{\mathrm{A}}}\right)^{-3 / m} f_{\mathrm{A}}\left[\sigma_{n \mathrm{~B}}\left(\frac{D_{\mathrm{B}}}{D_{\mathrm{A}}}\right)^{3 / m}\right]
$$

Equation (13) gives the expression for the shear strength envelope for granular material $\mathrm{B}$, on the basis of the expression for the shear strength envelope for granular material A.

The mathematical expression of the shear strength envelope for material A can be any of those usually used for granular materials; with De Mello's criterion (De Mello, 1977), the shear strength envelope is given by

$$
\tau_{\mathrm{f}}=A\left(\sigma_{\mathrm{n}}^{\prime}\right)^{b}
$$

where $\tau_{\mathrm{f}}$ is the maximum shear stress, $\sigma_{\mathrm{n}}^{\prime}$ is the effective normal stress, and $A$ and $b$ are material constants. Assuming now that the expression for the shear strength envelope for granular material $\mathrm{A}$ is given by equation (14) and characterised by the parameters $A_{\mathrm{A}}$ and $b_{\mathrm{A}}$, the expression for the shear strength envelope of granular material $\mathrm{B}$ can be derived from equation (13) as

$$
\begin{aligned}
\tau_{\mathrm{fB}} & =\left(\frac{D_{\mathrm{B}}}{D_{\mathrm{A}}}\right)^{-3 / m} \tau_{\mathrm{fA}} \\
& =A_{\mathrm{A}}\left(\frac{D_{\mathrm{B}}}{D_{\mathrm{A}}}\right)^{-3\left(1-b_{\mathrm{A}}\right) / m}\left(\sigma_{\mathrm{nB}}\right)^{b_{\mathrm{A}}}
\end{aligned}
$$

Observe that in equation (15) the coefficient $A_{\mathrm{A}}$ is modified by a size effect factor, but the power exponent $b_{\mathrm{A}}$ remains unchanged.

\section{VALIDATION WITH EXPERIMENTAL DATA}

A wide set of experimental results published independently by various authors has been analysed for this validation, including results by Lee (1992) and Marsal (1967), analysed in $\mathrm{Hu}$ (2009), and results from Marachi et al. (1969) and Charles \& Watts (1980), analysed in Frossard (2005a, 2006, 2009a, 2009c).

\section{Analysis of results by Lee (1992)}

Two limestone granular materials, subsequently termed MOLS (as material A) and POLS (as material B), with parallel gradations (Fig. 12(a)) and different particle sizes,

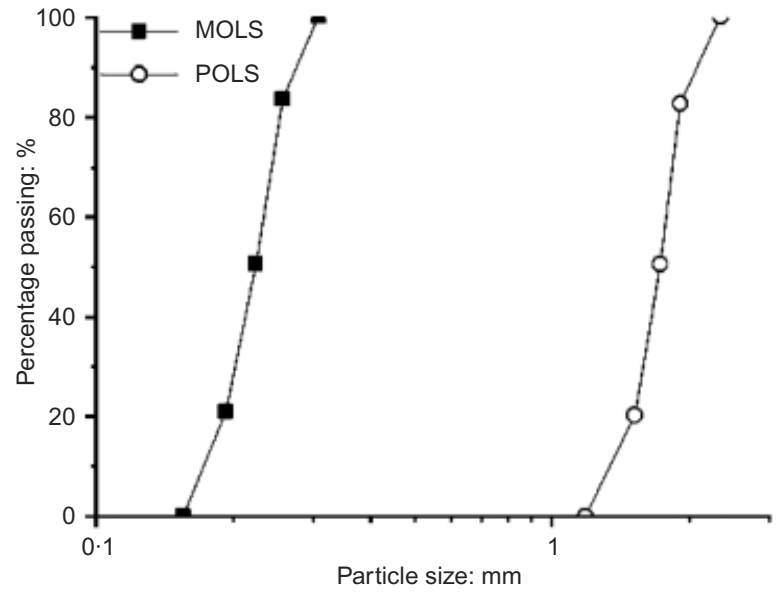

(a)

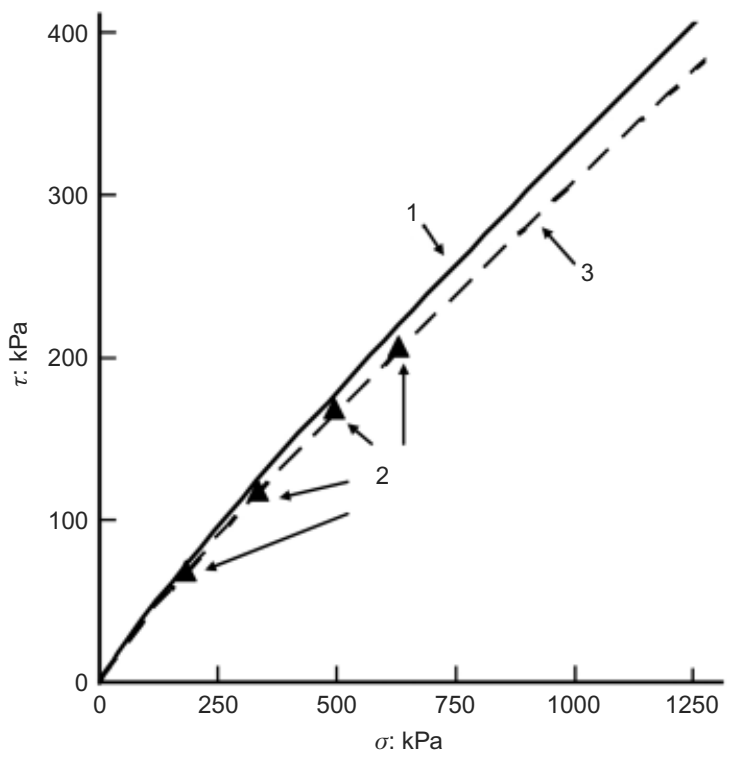

(b)

1 Experimental shear strength envelope for MOLS material 2 Experimental shear strength envelope for POLS material 3 Shear strength for POLS material extrapolated from MOLS material by using size effect rule

Fig. 12. (a) Parallel gradations for materials MOLS and POLS; (b) comparison of experimental and predicted shear strength envelopes (redrawn from data presented by Lee, 1992)

were chosen by Lee (1992), with the ratio between their respective mean grain diameters $D_{50}$ about 10 .

Crushing tests (Fig. 1) were performed on different particle sizes. The crushing strength function adjusted for this limestone (equation (1)) is

$$
\bar{f}=4 \cdot 51 \bar{d}^{1 \cdot 65}
$$

Sets of triaxial tests were performed by Lee (1992), defining the shear strength envelopes for both materials.

From triaxial experiment data, the shear strength envelope for material MOLS can be fitted according to

$$
\tau_{\mathrm{A}}\left(\sigma_{\mathrm{n}}\right)=0.71 \sigma_{\mathrm{n}}^{0.89}
$$

Choosing the characteristic diameter $D_{50}$ to represent the size ratio, $D_{50}(\mathrm{~A})=0.22 \mathrm{~mm}$ and $D_{50}(\mathrm{~B})=1.73 \mathrm{~mm}$ for materials MOLS and POLS respectively, the theoretical shear strength envelope for POLS can be predicted from equations (15) and (17) as

$$
\tau_{\mathrm{B}}\left(\sigma_{\mathrm{n}}\right)=0 \cdot 66 \sigma_{\mathrm{n}}^{0 \cdot 89}
$$


Shear strength envelopes obtained by this method and those from triaxial experiments have been compared (Fig. 12(b)). The theoretical prediction fits the experimental results very well, although the size effect is not very much marked in this example.

\section{Analysis of results from Marsal (1967)}

Marsal (1967) performed a series of triaxial experiments on silicified conglomerate rockfill used at El Infiernillo dam, with the specimen diameters and corresponding gradations shown in Fig. 13(a). Two different granular sizes are selected as materials $\mathrm{A}$ and $\mathrm{B}$, corresponding respectively to specimens $20 \mathrm{~cm}$ and $113 \mathrm{~cm}$ in diameter. The coefficients of uniformity for the two granular materials are nearly the same, at about 10 .

From particle-crushing tests data in Marsal (1967), $\lambda=1 \cdot 2$, so

$$
m=\frac{3}{2-\lambda}=3 \cdot 75
$$

For material A triaxial tests, the fitted equation of the shear strength envelope is (Fig. 13(b))

$$
\tau_{\mathrm{A}}\left(\sigma_{\mathrm{n}}\right)=1 \cdot 30 \sigma_{\mathrm{n}}^{0 \cdot 91}
$$

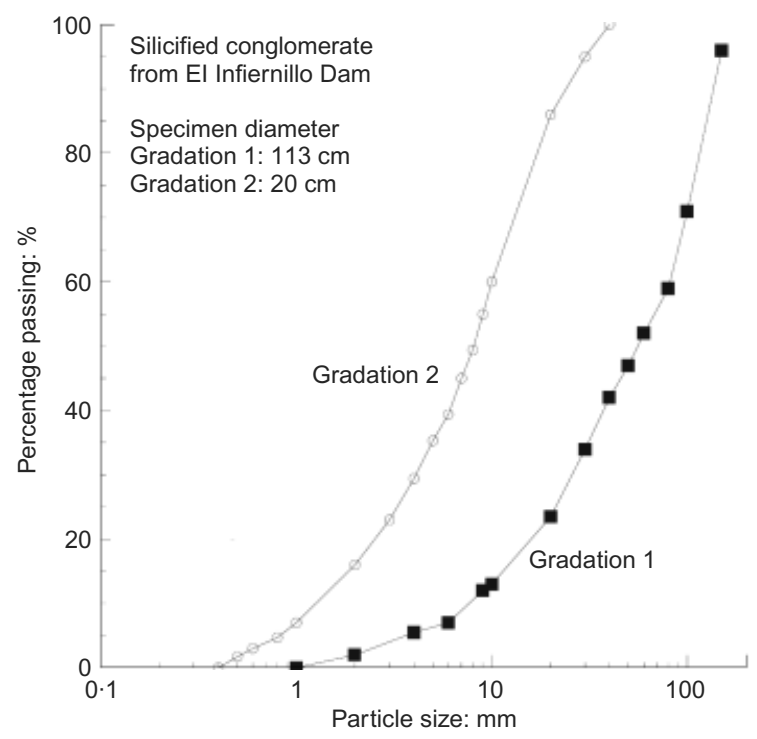

(a)

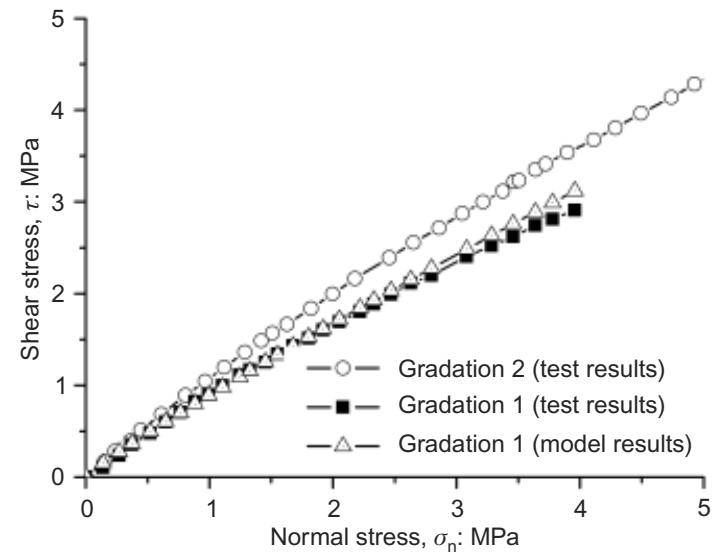

(b)

Fig. 13. (a) Gradation for El Infiernillo Dam material; (b) comparison of experimental and predicted shear strength envelopes for silicified conglomerate material (redrawn from data presented by Marsal, 1967)
Characteristic grain sizes are $D_{50}(\mathrm{~A})=6.8 \mathrm{~mm}$ and $D_{50}(\mathrm{~B})=68.9 \mathrm{~mm}$ for materials $\mathrm{A}$ and $\mathrm{B}$. Applying the size effect relation to the shear strength envelope of material A, the shear strength envelope for material $\mathrm{B}$ can be predicted as

$$
\begin{aligned}
\tau_{\mathrm{B}}(\sigma) & =\left(\frac{68 \cdot 9}{6 \cdot 8}\right)^{-3 / 3 \cdot 75} \tau_{\mathrm{A}}\left(\sigma_{\mathrm{n}}\right) \\
& =1 \cdot 30\left(\frac{68 \cdot 9}{6 \cdot 8}\right)^{-3(1-0 \cdot 91) / 3 \cdot 75} \sigma_{\mathrm{n}}^{0.91} \\
& =1 \cdot 10 \sigma_{\mathrm{n}}^{0.91}
\end{aligned}
$$

The comparison between the shear strength envelope obtained from the experimental results and the computed one (equation (21)) is shown in Fig. 13(b), and displays quite a good fit.

Analysis of results from Marachi et al. (1969)

As described earlier, three different sets of similar granular materials were investigated, first prepared with parallel gradations, as displayed in Fig. 5, and subsequently tested in triaxial apparatuses with the same initial compactness within each set.

The three source materials were

(a) a quarried sedimentary argillite used in Pyramid Dam, with angular, medium-resistance particles

(b) a quarried crushed basalt, with angular, quite strong particles

(c) a borrowed granular alluvium used in Oroville Dam, with strong, rounded cobbles, gravels and particles of finegrained amphibolite.

No statistical data on crushing tests of particles are available, so no direct determination of the Weibull parameter $m$ is possible. However, measurements of the global breakage factor $B \%$ by systematic comparison of gradations measured before and after testing allows the Weibull parameters to be evaluated for each set of materials. Indeed, the size effect relation first sets a correspondence between the stress states associated with the same grain breakage amount within similar materials. Thus, for similar materials $\mathrm{A}$ and $\mathrm{B}$, the data for breakage factor $B \%$ against confining stress should correspond with the same similarity as the failure envelopes. So the parameters $m$ can be fitted by adjusting the similarity factors on the breakage factor data, and then applying them to the correspondence between the shear strength envelopes.

The results of this fit on breakage factor data are displayed in Fig. 14(a), with $m$ values of 8.3, 9 and 7 for the three materials. The application of these adjusted similarity ratios to the internal friction data (Fig. 14(b)) is particularly good: the predicted shear strength envelopes for rockfill $\left(D_{\max }=150 \mathrm{~mm}\right)$, reconstituted from shear strength envelopes measured on gravel $\left(D_{\max }=12 \mathrm{~mm}\right)$, correspond well with the experimental data.

\section{Analysis of results from Charles \& Watts (1980)}

The data compilation published by Charles \& Watts (1980) gathers experimental shear strength data from numerous previous tests on granular fills and rockfills, shown as the hatched areas in Fig. 15(a), together with new experimental results, shown as curves $\mathrm{A}, \mathrm{B} 1, \mathrm{~B} 2$ and $\mathrm{C}$.

This original diagram displays some apparent distortion: the new experimental results of Charles \& Watts (outlined by the dotted ellipse) appear curiously shifted towards the upper right corner of the diagram, as compared with the 


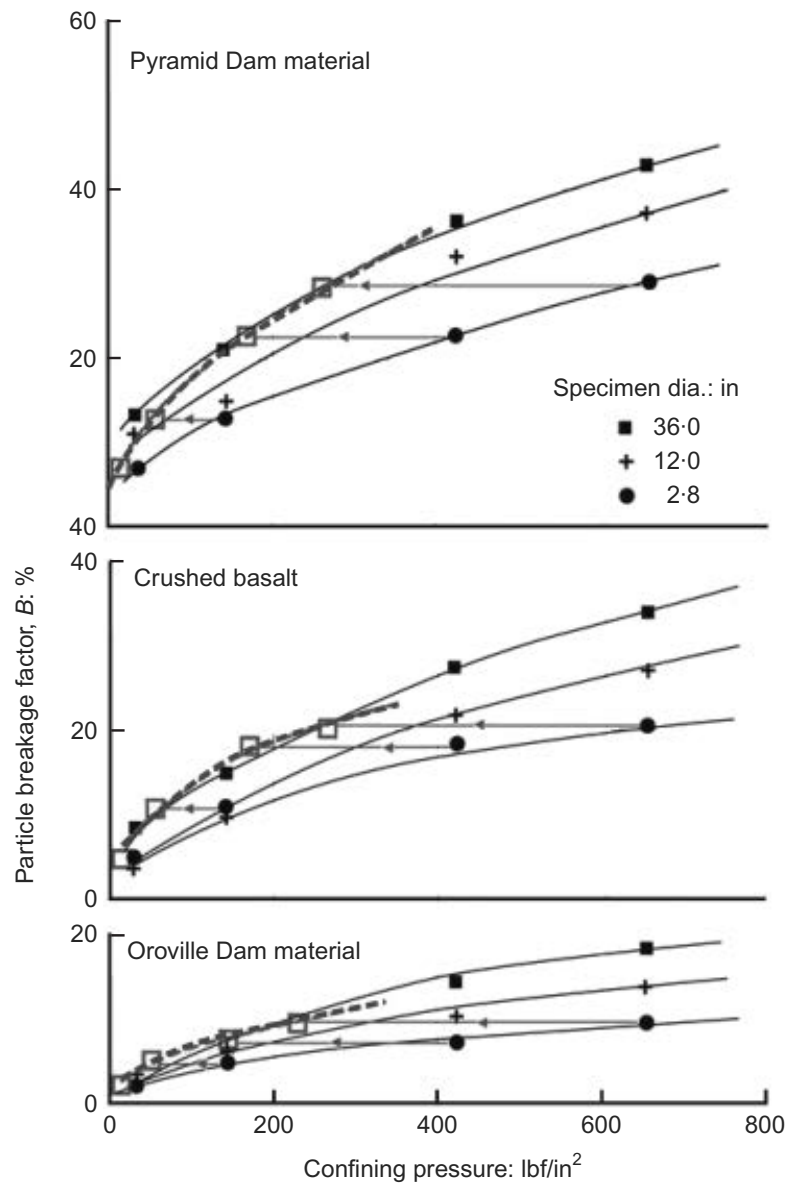

(a)

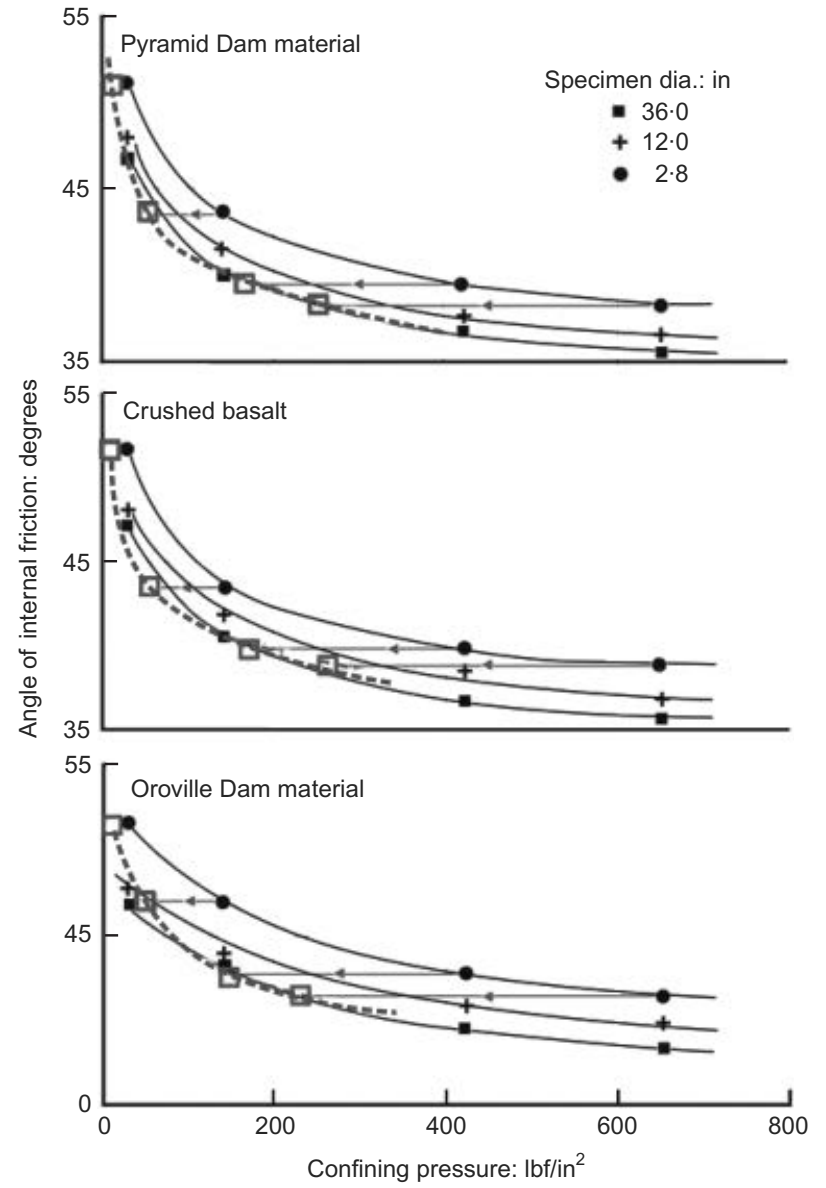

(b)

Fig. 14. For the three materials tested by Marachi et al. (1969): (a) adjusting size effect factors on grain breakage data against confining pressure; (b) application of size effect factors on internal friction data against confining pressure $(1 \mathrm{in}=25 \cdot 4 \mathrm{~mm}$; $\left.1 \mathrm{lbf} / \mathrm{in}^{2}=6.89 \mathrm{kPa}\right)$

older results of Marsal and Marachi. This holds also for slate material B2, deliberately chosen as weak by these authors, in order to complete the range of tested materials: so curve B2 should lie rather below the usual range of rockfill.

This apparent distortion can also be attributed to size effects, and corrected by the size effect relation. Indeed, the new measurements have been performed on granular materials limited to $D_{\max }=38 \mathrm{~mm}$, whereas the older results from Marsal and Marachi were drawn from coarser materials $\left(D_{\max }=150-180 \mathrm{~mm}\right)$. Here, the absence of data on particle breakage compels reliance on the central value $m=6$ for the Weibull parameter (see above). The corrected diagram (Fig. 15(b)) has been produced by this method, with a horizontal similarity factor on confining stresses of $\sqrt{ }(38 \mathrm{~mm} / 150 \mathrm{~mm})$ (this transformation is facilitated by the logarithmic scale used here for confining stresses: the similarity operation reduces to a simple shift of results towards the left).

This correction for size effects resolves the apparent distortion of the original diagram between the new results and the older ones.

\section{DISCUSSION ON SIZE EFFECT RELATION AND PRACTICAL APPLICATIONS}

Key assumptions involved in size effect relation

Three key assumptions have been made to reach the size effect relation (equation (10)) and its consequences, as follows. (a) The mineral particles constituting the granular materials under consideration do crush when the materials are strained, because of the development of pre-existing flaws and microcracks within the mineral matter, causing failures ruled primarily by the laws of fracture mechanics laws, with a predominant mode of particle failure by tensile-induced fracture, known as Mode I.

(b) The way these pre-existing flaws and microcracks are distributed in the material affect the variability of the particle crushing strength, whose statistics follow a Weibull distribution.

(c) Complete physical similarity is materially achievable (i.e. with reasonable accuracy) between granular materials constituted from a common homogeneous mineral source, compacted to the same density (i.e. the same void ratio) through similar compaction procedures.

Attention should be paid to the third of these key assumptions, as it may not be always satisfied with some granular materials, such as heterogeneous alluvium made of mixed sedimentary or metamorphic rocks, in which hard rocks predominate in the coarser fractions of granulometry, and weaker minerals accumulate in the finer fractions of granulometry.

A fourth key assumption is related to the implicit use of the size effect relation as a necessary and sufficient condition.

Starting from local contact forces, the size effect relation has been shown to be a necessary condition for obtaining the same amount of grain breakage. However it cannot be 


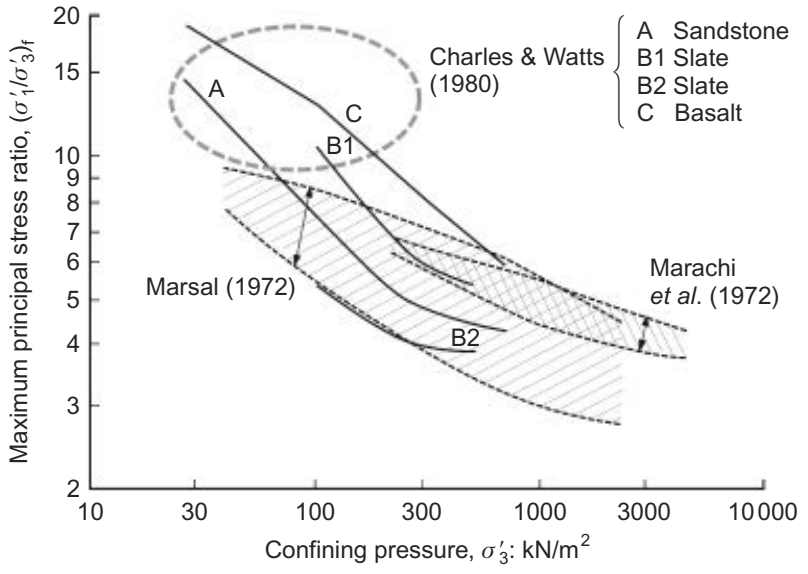

(a)

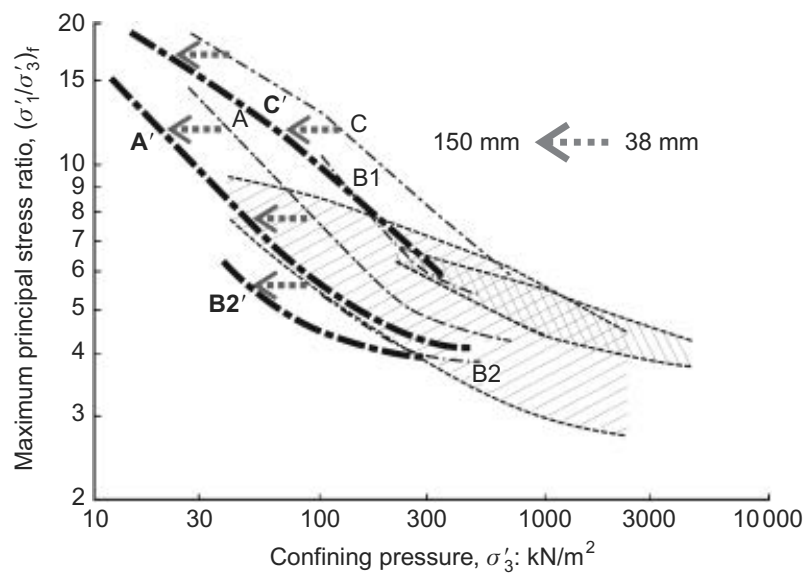

(b)

Fig. 15. (a) Data compilation on shear strength against confining stress by Charles \& Watts (1980); (b) Evidence of size effects in shear strength compilation

proved to be also a sufficient condition, because for a given macroscopic stress state, the corresponding distribution of local contact forces is not unique. Nevertheless, the validation on experimental data shows that, with a good level of approximation, it is also a sufficient condition for a wide range of granular materials.

\section{Rationale for a new practical method for rockfill shear strength determination}

The above results on size effects lead to a new rational method to assess, for a given material, the shear resistance envelope for rockfill, in a four-step procedure involving reasonable laboratory tests.

(a) From the rockfill under consideration, prepare a 'reduced' material, geometrically similar to the complete rockfill.

(b) Perform a large set of normalised rock mechanics crushing tests (Protodiakonov or Franklin tests), as a function of grain diameter, in order to adjust a Weibull distribution on the crushing strength distribution.

(c) Perform a set of shear tests (triaxial or others) on the reduced, gravel-sized material from the same stock (provided that the grain size distributions are geometrically similar, and compacted to the same porosities), in order to measure the shear strength envelope for the gravel-sized material.

(d) Use the size effect relation, with the measured Weibull parameter $m$, to assess the rockfill shear strength envelope from the measured gravel one.

Prudently limiting the scaling factor $\left(D_{\mathrm{B}} / D_{\mathrm{A}}\right)$ to 15 , this method makes it possible to assess the shear strength envelope of rockfill with $D_{\max }=600 \mathrm{~mm}$, representative of most of practical situations, from triaxial tests on gravelsized material with $D_{\max }=40 \mathrm{~mm}$, acceptable in a $250 \mathrm{~mm}$ diameter probe apparatus. This procedure, based on our new physical similarity rule, resulting from the laws of fracture mechanics governing particle breakage, makes it possible to reduce the material mass of a representative sample by a factor of $(1 / 15)^{3} \approx 1 / 3400$.

\section{Other practical applications of size effect relation}

An important consequence of the size effect relation is its relevance to safety margins and safety factors of compacted rockfill slopes. This material size effect has already been integrated in the limit equilibrium stability analysis method (Frossard, 2006, 2008, 2009a, 2009b, 2009c) by developing the previous work of Charles \& Soares (1984). The resulting method makes it possible to assess the relevance for safety factors of the recent trend towards the use of coarser materials in higher works with steeper slopes (Fig. 16). The results obtained have shown that direct extrapolation of midsized rockfill slopes to very high ones with coarser materials is likely to reduce the safety factors quite significantly.

To close the discussion on consequences of the size effect equation (10), consider stress-strain curves measured within two materials under complete physical similarity, sheared with confining stresses adjusted according to equation (10). For a given strain, the global amount of grain breakage will be the same in the two materials, and the principal stress ratio will also be the same. As a consequence, equation (10) should also set direct correspondences between the stressstrain curves in similar materials, which should also extend to critical state conditions.

Indeed, a material size effect has been detected in statistics for measured apparent rigidity modulus on a wide set of rockfill dam bodies (Hunter \& Fell, 2003), and the trend in the measured results has been found to correspond to the size effect relation (Frossard, 2009a). However, before this correspondence between stress-strain curves and (eventually) critical state conditions can be investigated further, it still needs to be thoroughly compared with detailed experimental data.

\section{Effect of change in void ratio}

The size effect relation links sets of similar materials made of the same mineral matter, with similar gradations (parallel on a log scale of grain size) and the same initial void ratios, implemented through similar compaction procedures. In such a situation, the correspondence between the internal friction and the amount of grain breakage has been found to be unique, regardless of the characteristic size (coarse-, medium- or fine-grained), if all the specimens of one set are given the same initial compactness (see Fig. 6, and other results from Marachi et al., 1969). So experimental curves such as those in Fig. 6 could be measured for various values of initial void ratio on fine-grained model material, as discussed above. Such experimental curves will also hold for the coarse rockfill corresponding to the model material.

\section{CONCLUSIONS}

A rational approach of the physics of size effects due to grain breakage in granular materials has been presented, which sets a new method for evaluating the mechanical behaviour of coarse granular materials widely used in civil works, through reasonable laboratory testing efforts. The wide set of experimental proofs presented has already shown 


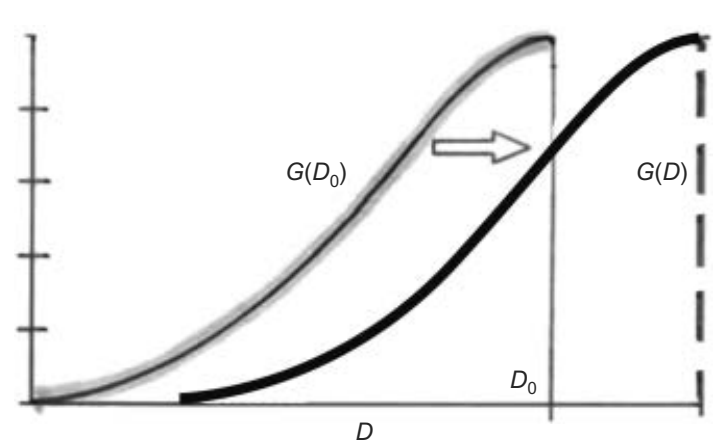

(a)

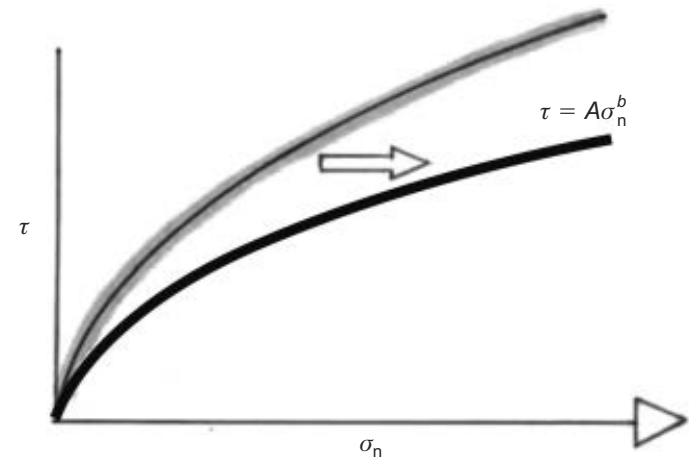

(b)

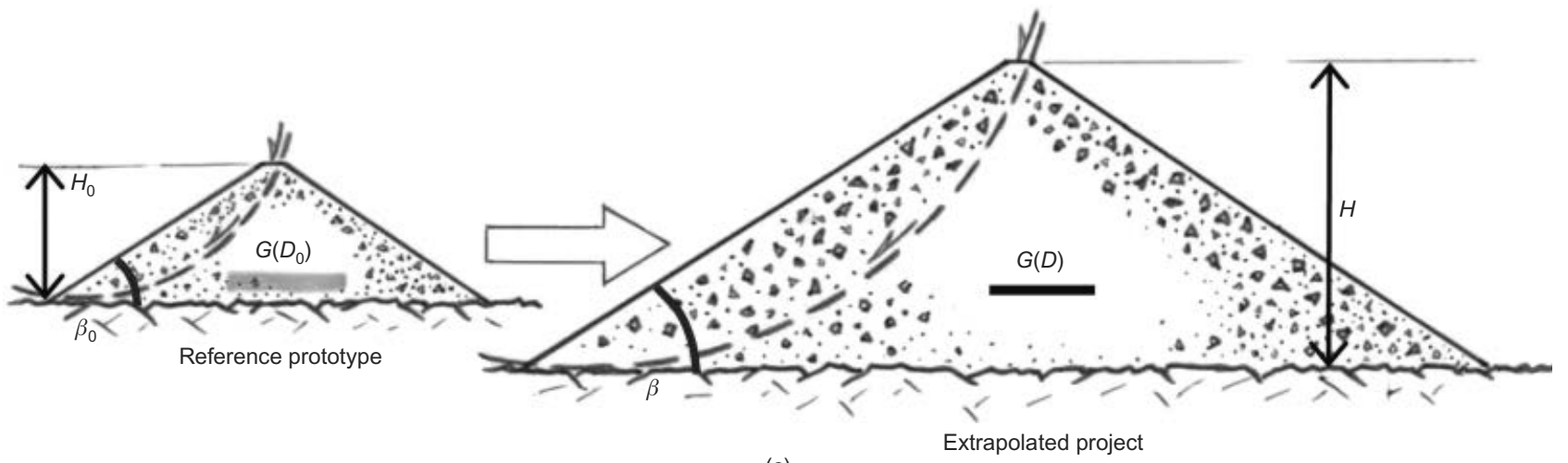

(c)

Fig. 16. Combined impacts of size effects and other key parameters on rockfill embankment safety factors: (a) granulometry; (b) shear strength; (c) size $H$ and slope $\beta$ of the works

the global validity of the approach. A significant programme is in progress in France to develop further confirmations of this validity, and explore its limitations through a wide experimental programme, including $1 \mathrm{~m}$ diameter triaxial tests. The key assumptions underlying the approach are simple, and are likely to be satisfied by many of the granular materials encountered in civil engineering practice, as confirmed by the experimental proofs presented. However, as outlined in the paper, some exceptions may be found with particular granular materials.

Significant practical applications have been developed, in the area of material testing methods, and in the area of stability analysis methods.

Finally, the present paper has been focused specifically on the effects of grain breakage on shear strength in granular materials. For a comprehensive insight into the physics underlying this shear strength in granular materials, the present results should be considered together with the properties resulting from the effects of friction, and other features such as gradation and compactness, grain shape and mineralogy (e.g. Frossard, 1979, 1983, 1986, 2001, 2005a, 2005b; Duncan, 2004).

\section{ACKNOWLEDGEMENTS}

This paper is part of a collective work under development since June 2008 in the French research Project ECHO, sponsored by the French Agence Nationale pour la Recherche (ANR), involving a wide partnership, including: EIFFAGE Travaux Publics; Electricité de France-CIH; Laboratoire de Mécanique des Solides from Ecole Polytechnique; Institut de Recherche en Génie Civil et Mécanique from Ecole Centrale Nantes; Centre d'Etudes Techniques de l'Equipement- Laboratoire Régional des Ponts et Chaussées Lyon; Coyne et Bellier IngénieursConseils (now incorporated in Tractebel Engineering), who originated the project and coordinated its implementation, as coordinating partner. The authors gratefully thank: Dr N. D. Marachi for permission to reproduce the original data shown in Figs 5, 6, 14(a) and 14(b) and Géotechnique journal for permission to reproduce the original data shown in Figs 15(a) and 15(b). The second author also wants to acknowledge the financial support provided by the Chinese Scholarship Council.

\section{NOTATION}

$A, b$ material parameters in De Mello failure criterion

$D_{\mathrm{A}}, D_{\mathrm{B}}$ characteristic lengths or sizes for granular materials A and B respectively (e.g. maximum grain size $D_{\max }$, mean grain size $D_{50}$, or other given length)

$\bar{d}$ average diameter of a set of particles

$\bar{f}$ average crushing resistance (force) measured on a set of particles

$\boldsymbol{f}_{(n / p)}$ contact force (vector) exerted by particle $n$ on particle $p$

$f_{\mathrm{A}}, d_{\mathrm{A}}$ fixed crushing force exerted on a set of particles of given diameter

$\left\{\boldsymbol{f}_{\mathrm{A}}\right\}$ set of contact forces (vectors) within granular material A

$\boldsymbol{l}_{(n / p)}$ branch vector joining centres of particles in contact, from particle $n$ towards particle $p$

$m$ material parameter in Weibull statistical distribution

$P_{\mathrm{s}}$ probability of survival

$V$ volume

$\eta, \lambda$ experimental material parameters in Marsal crushing strength formula

$\sigma$ stress

$\sigma, \sigma_{\mathrm{ij}}$ macroscopic stress tensor and its components

$\tau_{\mathrm{A}}, \sigma_{\mathrm{nA}}$ shear stress and normal stress at failure in granular material A

\section{REFERENCES}

Barton, N. \& Kjaernsli, B. (1981). Shear strength of rockfills. J. Geotech. Engng ASCE 107, No. 7, 873-891. 
Bazant, Z. P. \& Planas, J. (1998). Fracture and size effect in concrete and other quasibrittle materials. London: CRC Press.

Becker, E., Chan, C. K. \& Seed, H. B. (1972). Strength and deformation characteristics of rockfill materials in plane strain and triaxial compression tests, Report No. TE-72·3. Department of Civil and Environmental Engineering, University of California, Berkeley.

Biarez, J. \& Hicher, P. Y. (1997). Influence de la granulométrie et de son évolution par ruptures de grains sur le comportement mécanique de matériaux granulaires. Rev. Fr. Génie Civ. 1, No. 4, 607-631.

Bolton, M. D. (1986). The strength and dilatancy of sands. Géotechnique 36, No. 1, 65-78, http://dx.doi.org/10.1680/geot.1986. 36.1.65

CBDB-ICOLD (2007). Proc. 3rd Symp. on Concrete Face Rockfill Dams, Florianopolis.

Chang, C. S. \& Hicher, P. Y. (2005). An elasto-plastic model for granular materials with microstructural consideration. Int. $J$. Solids Struct. 42, No. 14, 4258-4277.

Charles, J. A. \& Soares, M. M. (1984). Stability of compacted rockfill slopes. Géotechnique 34, No. 1, 61-67, http://dx.doi. org/10.1680/geot.1984.34.1.61

Charles, J. A. \& Watts, K. S. (1980). The influence of confining pressure on the shear strength of compacted rockfills. Géotechnique 30, No. 4, 353-367, http://dx.doi.org/10.1680/geot.1980. 30.4.353.

Chávez, C. \& Alonso, E. E. (2003). A constitutive model for crushed granular aggregates which includes suction effects. Soils Found. 43, No. 4, 215-227.

Christofferson, J., Mehrabadi, M. M. \& Nemat-Nasser, S. (1981). A micromechanical description on granular material behavior. J. Appl. Mech. ASME 48, No. 2, 339-344.

Coop, M. R. \& Lee, I. K. (1993). The behavior of granular soils at elevated stresses. In Predictive soil - proceedings of the Wroth memorial symposium (eds G. T. Houlsby and A. N. Schofield), pp. 186-198. London: Thomas Telford.

Daouadji, A., Hicher, P.-Y. \& Rahma, A. (2001). An elastoplastic model for granular materials taking into account grain breakage. Eur. J. Mech. A Solids 20, No. 1, 113-137.

De Mello, V. F. B. (1977). Reflections on design decisions of practical significance to embankment dams. Géotechnique 27, No. 3, 281-355, http://dx.doi.org/10.1680/geot.1977.27.3.281.

Deluzarche, R. \& Cambou, B. (2006). Discrete numerical modelling of rockfill dams. Int. J. Numer. Anal. Methods Geomech. 30, No. 11, 1075-1096.

Duncan, J. M. (2004). Friction angles for sand, gravel, and rockfill. Kenneth Lee Memorial Seminar, Long Beach, CA, 13 pp.

Frossard, E. (1979). Effect of sand grain shape on interparticle friction: indirect measurements by Rowe's stress-dilatancy theory. Géotechnique 29, No. 3, 341-350, http://dx.doi.org/10.1680/ geot.1979.29.3.341; Discussion by W. B. Whalley (1982), 32, No. 2, 161-165, http://dx.doi.org/10.1680/geot.1982.32.2.161.

Frossard, E. (1983). Une règle d'écoulement simple pour les milieux granulaires. Géotechnique 33, No. 1, 21-29, http:// dx.doi.org/10.1680/geot.1983.33.1.21 (in French)

Frossard, E. (1986). Dilatance, dissipation d'énergie et critère de rupture tridimensionnel dans les matériaux granulaires. Rev. Fr. Géotech., No. 34, 17-31 (in French).

Frossard, E. (2001). L'approche énergétique en mécanique des matériaux granulaires. Poudres \& Grains, No. NS-2, 1-56 (in French).

Frossard, E. (2005a). Comportement macroscopique des matériaux granulaires mis en oeuvre dans les barrages, Special Report in French Research Project Micromechanics of Rockfill Dams, sponsored by the French Ministry of Research and Technology, Paris (in French).

Frossard, E. (2005b). A micromechanical constitutive law resulting from energy dissipation by friction. Proc. 5th Int. Conf. on Powders and Grains, Stuttgart 1, Part 1, 141-145.

Frossard, E. (2006). A new energy approach in granular media mechanics: applications to rockfill dams. Proc. 22nd Int. Congress on Large Dams, Barcelona 5, 191-208.

Frossard, E. (2008). Seguridad de grandes presas de escollera: efectos de escala en la resistencia al corte, y en los factores de seguridad. Senior Lecture. Actas Jornada Técnica Geotecnia de Presas. Madrid: Sociedad Española de Presas y Embalses (in Spanish).
Frossard, E. (2009a). On the structural safety of large rockfill dams. Proc. 23rd Int. Congress on Large Dams, Brasilia, Q.91-R.39 (CD-ROM).

Frossard, E. (2009b). Scale effects in large rockfill dams behaviour and safety margins. Keynote lecture. Proc. 10th ICOLD Benchmark Workshop on Numerical Analysis of Dams, Paris (CD-ROM).

Frossard, E. (2009c). Effets d'échelle dans la résistance au cisaillement des remblais granulaires et dans la stabilité de grands ouvrages en enrochements. Proc. 17th Int. Conf. Soil Mech. Geotech. Engng, Alexandria 1, 97-101 (in French).

Frossard, E. (2009d). La relation d'effet d'échelle sur les courbes intrinsèques dans les matériaux granulaires du génie civil: Bases physiques, ECHO Research Project internal report. Paris: Coyne et Bellier (in French).

Griffith, A. A. (1921). The phenomena of rupture and flow in solids. Phil. Trans. R. Soc. London A 221, No. 587,163-198.

Hardin, B. O. (1985). Crushing of soil particles. J. Geotech. Engng $A S C E$ 111, No. 10, 1177-1192.

$\mathrm{Hu}, \mathrm{W}$. (2009). Contribution à l'étude de l'effet d'échelle dans les matériaux granulaires. $\mathrm{PhD}$ thesis, Ecole Centrale de Nantes (in French).

Hunter, G. \& Fell, R. (2003). Rockfill modulus and settlement of concrete faced rockfill dams. J. Geotech. Geoenviron. Engng ASCE 129, No 10, 909-917.

ICOLD (2002). Concrete face rockfill dams: Concepts for design and construction. Paris: International Commission on Large Dams, Committee on Materials for Fill Dams.

Indraratna, B., Ionescu, D. \& Christie, H. D. (1998). Shear behaviors of railway ballast based on large-scale triaxial tests. J. Geotech. Geoenviron. Engng ASCE 124 No. 5, 439449

Lackenby, J., Indraratna, B., McDowell, G. \& Christie, D. (2007). Effect of confining pressure on ballast degradation and deformation under cyclic triaxial loading. Géotechnique 57, No. 6, 527536, http://dx.doi.org/10.1680/geot.2007.57.6.527.

Lade, P. \& Bopp, P. A. (2005). Relative density effects on drained sand behavior at high pressures. Soils Found. 45, No. 1, 1-13.

Lee, D. M. (1992). The angles of friction of granular fills. $\mathrm{PhD}$ thesis, Cambridge University.

Love, A. E. H. (1927). A treatise on the mathematical theory of elasticity. Cambridge: Cambridge University Press.

McDowell, G. R. \& Bolton, M. D. (1998). On the micromechanics of crushable aggregates. Géotechnique 48, No. 5, 667-679, http://dx.doi.org/10.1680/geot.1998.48.5.667.

Marachi, N. D., Chan, C. K., Seed, H. B. \& Duncan, J. M. (1969). Strength and deformation characteristics of rockfills materials, Report No. TE-69-5. Department of Civil Engineering/Geotechnical Engineering, University of California, Berkeley.

Marachi, N. D., Chan, C. K. \& Seed, H. B. (1972). Evaluation of properties of rockfill materials. J. Soil Mech. Found. Div. 98, No. SM1, 95-114.

Marsal, R. J. (1967). Large-scale testing of rockfills materials. J. Soil Mech. Found. Engng Div. ASCE 93, No. 2, 27-44.

Marsal, R. J. (1972). Mechanical properties of rockfill. In Embankment dam engineering: Casagrande volume (eds R. C. Hirschfeld and S. J. Poulos), pp. 109-200. New York: Wiley.

Miura, S., Yagi, K. \& Asonuma, T. (2003). Deformation-strength evaluation of crushable volcanic soils by laboratory and in-situ testing. Soils Found. 43, No. 4, 47-57.

Nakata, Y., Hyde, A. F. L., Hyodo, M. \& Murata, H. (1999). A probabilistic approach to sand crushing in the triaxial test. Géotechnique 49, No. 5, 567-583, http://dx.doi.org/10.1680/ geot.1999.49.5.567.

Rothenburg, L. \& Selvadurai, A. P. S. (1981). Micromechanical definitions of the Cauchy stress tensor for particular media. In Mechanics of structured media (ed. A. P. S. Selvadurai), pp. 469-486. Amsterdam: Elsevier Science.

Weber, J. (1966). Recherches concernant les contraintes intergranulaires dans les milieux pulvérulents. Bull. Liaison des Ponts et Chaussées Paris, No. 20, 1-20 (in French).

Weber, J. (1971). Les applications de la similitude physique aux problèmes de la mécanique des sols. Paris: Eyrolles et Gauthier Villars (in French).

Weibull, W. (1951). Statistical distribution function of wide applicability. J. Appl. Mech. ASCE 18, No. 3, 293-297. 